\title{
Attachment of virulent Treponema pallidum to human mononuclear phagocytes
}

\author{
BARRY D. BRAUSE AND RICHARD B. ROBERTS \\ From the Division of Infectious Diseases, Department of Medicine, \\ Cornell University Medical College, New York, USA
}

SUMmARY The predominant phagocyte in established human syphilitic lesions is the mononuclear phagocyte. As these leucocytes may be important in immunity to Treponema pallidum, the initial interaction between human phagocytes and pathogenic $T$. pallidum (Nichols strain) was studied in vitro. Motile, virulent $T$. pallidum attach to the surface membrane of phagocytes but are not ingested by these cells. Heated, non-motile treponemes are not cell-associated but are observed free in the extracellular medium. Attachment is polar, at one or both terminal portions of the treponeme, and is neither serum- nor complement-dependent. Ingestion of virulent treponemes was not observed by phase-contrast or by electron microscopy in the presence of normal human or rabbit serum and complement. Techniques were chosen to preserve both the fragile surface constituents of the treponeme and the phagocytic function of mononuclear cells. Unfixed preparations were observed by phase-contrast microscopical examination during incubation to differentiate motile from non-motile organisms and fixed preparations were used for quantitation of attachment. This model should be useful for studying humoral and cell-mediated immunity in syphilis.

\section{Introduction}

The inflammatory response in human syphilis is characterised by plasma cells, macrophages, and lymphocytes (Robbins, 1967). Furthermore, the principal phagocytic cell in histological sections of syphilitic chancres, condylomata lata, the maculopapular rash of secondary syphilis and in gummas is the mononuclear phagocyte. Previous studies of non-pathogenic Treponema refringens-rabbit peritoneal macrophage interactions revealed intracellular treponemes within vacuoles (Musher et al., 1972). However, the initial interaction between virulent viable Treponema pallidum and animal or human monocytes has not been previously reported.

The complex process of phagocytosis may be divided into three sequential steps: attachment of the microbe to the surface membrane of the phagocytic cells, ingestion of the attached microbe, and digestion. Knowledge of these biological processes in $T$. pallidum-phagocyte interactions would greatly help our understanding of the pathophysiology of syphilis in humans. This report describes the initial

Address for reprints: Dr B. D. Brause, Division of Infectious Diseases, Cornell University Medical College, New York, NY 10021, USA

Received for publication 21 December 1977 interaction or attachment in vitro of $T$. pallidum to human mononuclear leucocytes.

\section{Materials and methods}

\section{PREPARATION OF T. PALLIDUM}

Virulent $T$. pallidum (Nichols strain) obtained from the laboratory of Dr Paul H. Hardy, Johns Hopkins Medical Institutions, was used. The organism was cultivated in the testes of Venereal Disease Research Laboratory-negative (VDRL-negative), New Zealand white rabbits. An inoculum of $10^{6}$ treponemes in $10 \%$ heat-inactivated rabbit serum (Microbiological Associates, Inc., Bethesda, Maryland) produced a palpable orchitis in 9-11 days when rabbits were housed in air-conditioned quarters $\left(15-17^{\circ} \mathrm{C}\right)$ and were given intramuscular hydrocortisone sodium phosphate (Merck and Co., West Point, Pennsylvania), $6 \mathrm{mg} / \mathrm{kg}$ daily starting 48 hours after inoculation. Within two days of the development of fulminant orchitis, animals were killed with pentobarbitone sodium $(50 \mathrm{mg} / \mathrm{kg}$, i.v.) and the testes removed aseptically. Each testis was sliced with sterile scissors, and tissue sections were vortexed intermittently for 20 minutes in $1.5 \mathrm{ml}$ of RPMI-1640 tissue culture medium without antibiotics (Grand Island Biological Co., Grand Island, 
NY). The extraction mixture was then centrifuged at $1200 \mathrm{~g}$ for 10 minutes to sediment gross tissue debris, testicular cells, and spermatozoa, and the concentration of treponemes in the supernate adjusted to $5 \times 10^{7}-2 \times 10^{8}$ treponemes per millilitre (Magnuson et al., 1948). Treponemes obtained by this aerobic extraction method were 99-100\% actively motile and retained their motility and infectivity for at least three hours in an aerobic atmosphere. Studies were also performed using non-motile treponemes which had been heated at $56^{\circ} \mathrm{C}$ for five minutes.

Treponemes were also harvested by an anaerobic technique incorporating the motility-sustaining medium used in the Treponema pallidum immobilisation (TPI) test described by Nelson and Diesendruck (1951) and modified by Metzger et al. (1961). This medium was further modified by the use of RPMI-1640 tissue culture medium instead of $0.85 \% \mathrm{NaCl}$ as the gelatin solvent. Whereas the aerobic extraction method took only 20 minutes, this technique took two hours.

\section{PREPARATION OF HUMAN MONONUCLEAR}

CELLS

Heparinised peripheral blood was pipetted on to Ficoll (Pharmacia Chemicals, Uppsala, Sweden)Hypaque (Winthrop Laboratories, New York, NY) gradients (24 parts of $9 \%$ Ficoll to 10 parts of $50 \%$ Hypaque), using a modification of the method of Gordon et al. (1974). Sterile plastic materials were used throughout the procedure. The gradient was centrifuged for 40 minutes at $220 \mathrm{~g}$. A central zone containing phagocytes, lymphocytes, and platelets was removed, and the cells were washed three times with $10 \mathrm{ml}$ phosphate-buffered saline (calcium- and magnesium-free) containing $1 \mathrm{ml}$ EDTA $(0.15 \mathrm{~mol} / \mathrm{l})$ per $5 \mathrm{C0} \mathrm{ml}$. After centrifugation for 10 minutes at $340 \mathrm{~g}$, the pellet was resuspended in the desired volume of RPMI-1640 tissue culture medium (without antibiotics) containing $5 \%$ heat-inactivated human serum to obtain a final concentration of $5 \times 10^{6}$ cells (phagocytes and lymphocytes) per millilitre. Aliquots containing $0.2 \mathrm{ml}$ of the cell suspension were then placed on sterile $15 \mathrm{~mm}$ round glass coverslips in $10 \times 35 \mathrm{~mm}$ Petri dishes and incubated in $5 \% \mathrm{CO}_{2} / 95 \%$ air for 90 minutes at $37^{\circ} \mathrm{C}$. Phagocytes adhered to the glass surface, while lymphocytes and platelets were washed off with additional tissue culture medium. The monolayers were then stored in serum-free RPMI-1640 tissue culture medium at $37^{\circ} \mathrm{C}$ in $5 \% \mathrm{CO}_{2}$ for varying times ranging from 15 minutes to 14 days before use. Culture medium was changed every 48 hours.
SERUM

Normal rabbit serum was collected from VDRLnegative animals. Human serum was obtained from VDRL-negative volunteers who had no history of syphilis. Human serum and human phagocytes were autologous. All sera were used immediately or stored in small aliquots at $-65^{\circ} \mathrm{C}$. Serum was frozen once and thawed immediately before each experiment. In certain experiments, serum was heat-inactivated at $56^{\circ} \mathrm{C}$ for 30 minutes.

\section{T. PALLIDUM-HUMAN MONOCYTE}

INTERACTIONS

Glass coverslips with adherent human phagocytes were placed in cylindrical vials. Suspensions containing $2 \cdot 5-5 \times 10^{7}$ treponemes in tissue culture medium were added in $0.5 \mathrm{ml}$ amounts to mononuclear cell monolayers with or without $20 \%$ fresh or heat-inactivated normal human or rabbit serum. Certain mixtures also contained $0.025 \mathrm{ml}$ guinea-pig complement (Grand Island Biological Co., Grand Island, NY) which represented approximately 700 log units/ml (Hederstedt, 1961).

To ensure that testicular preparations did not interfere with phagocytosis, control incubations with inert, ingestable polystyrene latex particles (Dow Chemicals, Indianapolis, Indiana) with a $1.099 u \mathrm{~m}$ diameter were used in all experiments (Griffin and Silverstein, 1974). Control mixtures contained $0.5 \mathrm{ml}$ of the treponeme suspension with or without serum and $10^{8}$ latex particles. Serum was added in $0.1 \mathrm{ml}$ volumes to comprise $20 \%$ of the incubating mixtures, and latex particles represented $0.05 \mathrm{ml}$ of the total volume.

\section{MICROSCOPY}

Initially, unfixed, wet preparations of $T$. pallidum phagocyte mixtures were examined at a magnification of $\times 756$ in a phase-contrast oil immersion system for periods of two to three hours at $37^{\circ} \mathrm{C}$ in air. Preparations were made by inversion of coverslips with adherent cells on to approximately $3 \mu 1$ of treponeme suspension. Coverslip edges were sealed with paraffin.

Treponeme-phagocytemixtures werealso incubated at $37^{\circ} \mathrm{C}$ in $5 \% \mathrm{CO}_{2} / 95 \%$ air. After 60 minutes the coverslips with adherent phagocytes and treponemes were washed with RPMI-1640 tissue culture medium and fixed with $2.5 \%$ glutaraldehyde in $0.1 \mathrm{~mol} / 1$ sodium cacodylate buffer ( $\mathrm{pH} 7 \cdot 40)$. Coverslips were mounted and sealed on glass slides for phasecontrast microscopical examination. Quantitative evaluations were made a few hours after fixation by determining the numbers of cell-attached and unattached organisms per 50 treponemes. Calculated percentages of attached treponemes repre- 
sented the proportion of the total number of treponemes remaining on the glass coverslip after incubation, washing, and fixation, which were adherent to leucocyte cell surfaces (Table 1). The density of phagocytes and treponemes per coverslip was determined by multiplying the mean number of phagocytes or treponemes per $\times 756$ microscopic field by $4.4 \times 10^{3}$. The microscopic field area was $0.04 \mathrm{~mm}^{2}$, the coverslip area $177 \mathrm{~mm}^{2}$. Generally there were $3.12 \times 10^{4}$ cells per coverslip, and the average density of treponemes per coverslip was $2.82 \times 10^{4}$ for virulent motile treponemes and $1.52 \times 10^{4}$ for heated, non-motile treponemes.

\section{Results}

MORPHOLOGICAL OBSERVATIONS DURING INCUBATION

The interaction between virulent $T$. pallidum (Nichols strain) and human phagocytes was first studied using unfixed, wet preparations. Examination by phase-contrast at $37^{\circ} \mathrm{C}$ showed that treponemes attached themselves to the cell surface. Attachment was observed within five minutes of incubation and was polar with one or both terminal portions of the treponeme in contact with the cell surface (Fig. 1). Although firmly attached at one end to the phagocyte, treponemes retained their characteristic motility with both spiral and flexion movements. Motility was maintained for at least $2 \frac{1}{2}$ hours in an aerobic atmosphere. Heat-killed, non-motile treponemes did not attach to the cell surface but remained free in the surrounding medium.

The morphology of human monocytes derived from peripheral blood changed during in vitro cultivation on a glass surface. At first adherent cells were rounded with a relatively small surface area. After 24 hours the cells resembled tissue macro-

Table 1 Attachment of virulent, motile T. pallidum $(T p)$ to human mononuclear leucocytes with or without normal serum

\begin{tabular}{|c|c|c|c|c|}
\hline & \multicolumn{2}{|c|}{ Aerobic extraction of $T p$} & \multicolumn{2}{|c|}{$T P I$ test extraction of $T p$} \\
\hline & $\%$ attached $T p^{*}$ & $\%$ cells with attached $T p$ & $\%$ attached $T p^{*}$ & $\%$ cells with attached $T p$ \\
\hline No serum & $\begin{array}{l}89 \\
(75-98)\end{array}$ & $\begin{array}{l}48 \\
(38-63)\end{array}$ & $\begin{array}{l}93 \\
(92-94)\end{array}$ & $\begin{array}{l}39 \\
(35-42)\end{array}$ \\
\hline \multicolumn{5}{|c|}{$20 \%$ heat-inactivated normal serum } \\
\hline $\begin{array}{l}\text { Human } \\
\text { Rabbit }\end{array}$ & $\begin{array}{l}85 \\
(75-92) \\
91 \\
(73-97)\end{array}$ & $\begin{array}{l}46 \\
(38-72) \\
48 \\
(32-69)\end{array}$ & $\begin{array}{l}91 \\
(89-94) \\
87 \\
(83-90)\end{array}$ & $\begin{array}{l}35 \\
(32-39) \\
39 \\
(38-40)\end{array}$ \\
\hline
\end{tabular}

Values represent the mean and range of three to five experiments

* Percentage of the total number of treponemes remaining on the glass coverslip after incubation, washing, and fixation adhering to leucocyte cell surfaces

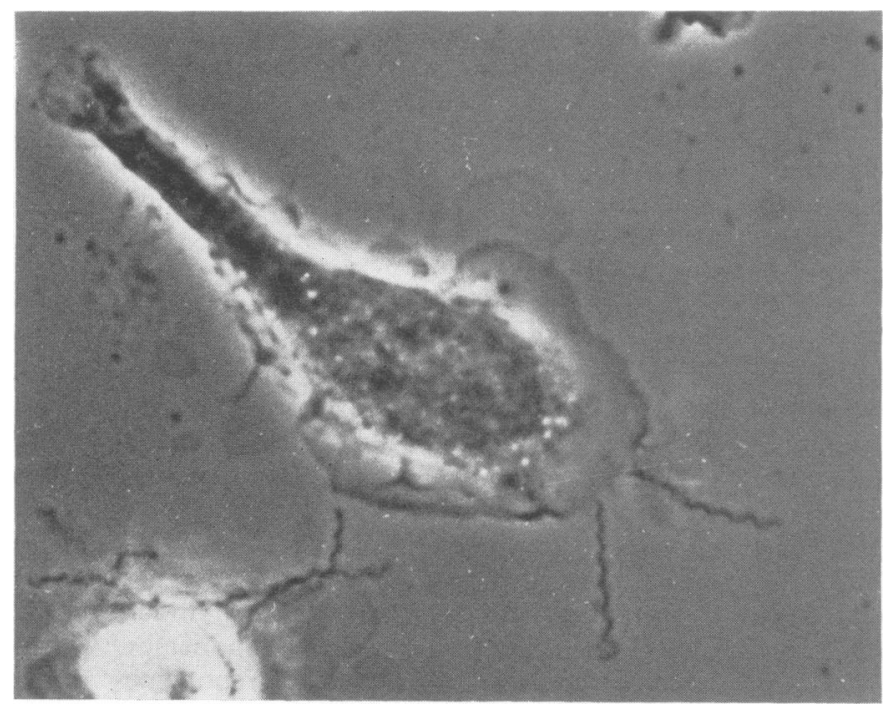

Fig. 1 Polar attachment of T. pallidum to surface membrane of a human mononuclear phagocyte under phase-contrast microscopy ( 1260$)$. 
phages with spreading of the cytoplasm and the presence of a ruffled membrane on the cell surface. The cytoplasm continued to spread with longer durations of cultivation. The nucleus and prominent nucleoli remained unchanged. During the 2-3 hour incubation of phagocytes with treponeme suspensions no morphological changes were seen-that is, vacuolisation did not occur and changes did not appear in the ruffled membrane. Treponemes attached themselves in a similar manner to those rounded mononuclear cells which were maintained on glass coverslips for 15 minutes as well as to those with large cytoplasmic surfaces which had been incubated for 14 days. Phagocytes were routinely cultivated in vitro for 2-3 days before incubation with suspensions of treponemes (Fig. 1). Attachment of T. pallidum was also observed at the surfaces of rabbit peripheral mononuclear leucocytes and unstimulated mouse peritoneal macrophages.

Ingestion of $T$. pallidum was not seen even when individual attached treponemes were observed for as long as 40 minutes with or without $20 \%$ fresh or heat-inactivated normal human or rabbit serum. In addition, heat-killed, non-motile organisms were not ingested under similar experimental conditions. Ingestion of polystyrene latex particles was observed under all of these conditions.

\section{MORPHOLOGICAL OBSERVATIONS AFTER}

FIXATION

The frequency of attachment was quantitated using glutaraldehyde-fixed preparations after 60 minutes of aerobic incubation. As shown in Table 1, 79-98\% (mean of $89 \%$ ) of treponemes extracted by either the aerobic or the TPI test technique were attached to phagocytes with or without $20 \%$ heat-inactivated normal human or rabbit serum $(\mathrm{P}>0.05){ }^{*}$ As previously stated the percentages of attached treponemes represent that proportion of the total number of treponemes remaining on the glass coverslip which were adherent to cell surfaces after incubation, washing, and fixation. Almost half the phagocytes had one treponeme or more attached to the cell surface. The treponeme density approximated that of the macrophages in these fixed preparations. No intracellular organism was detected by phase-contrast microscopy.

A control incubation mixture containing leucocytes, aerobically-prepared treponemes, and latex particles was included in all experiments to show that the treponeme suspension did not inhibit phagocytosis. Numerous intracellular latex particles were observed in the presence of attached treponemes (Fig. 2). Latex particles were added to preparations at the beginning or 15 minutes before the end of incubation. Over $90 \%$ of phagocytes ingested latex particles under either of these conditions indicating that the phagocytic function of the cells was intact. Treponemes harvested by the standard anaerobic method of the TPI test were also incubated with macrophages and latex particles. The results of these experiments performed in triplicate showed that whereas the technique of extraction had no effect on the frequency of attachment of treponemes, the ingestion of latex particles was inhibited suggesting that the TPI test medium

*Statistical analysis was by a $t$ test with 25 degrees of freedom where $t=0.3686$

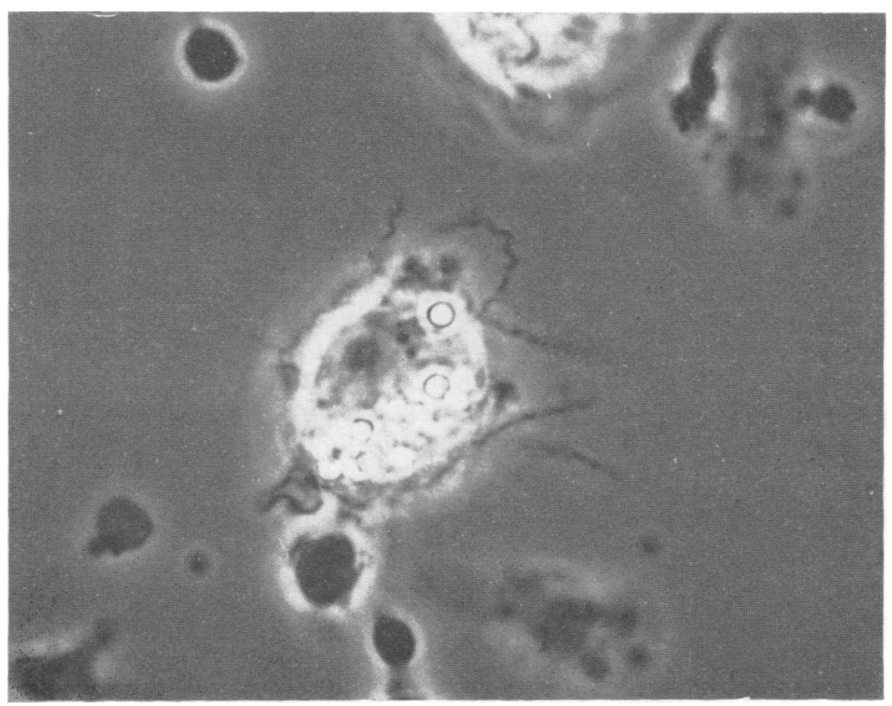

Fig. 2 Intracellular latex particles in a human mononuclear phagocyte with attached T. pallidum by phase-contrast microscopy. Note horse-shoe configuration of one treponeme attached at both ends to the cell surface $(\times 1008)$. 
may interfere with phagocytosis. Furthermore, phagocytes incubated with latex particles suspended in TPI test medium (without treponemes) failed to ingest the latex particles. TPI test medium was therefore not used in subsequent studies.

As $T$. pallidum in the absence of serum and complement attached to the cell surface regardless of the extraction procedure (Table 1), attachment was not due to complement-dependent immune adherence (Nelson, 1953). However, complement in association with antibody present in the testicular preparation or in normal serum may be required for the ingestion of attached organisms. The presence of fresh sera or complement had no effect on attachment $(\mathrm{P}>0.05) \dagger$ (Table 2$)$. In addition, intracellular treponemes were not observed in preparations containing fresh serum or heatedinactivated serum supplemented with guinea-pig complement.

Table 2 Effect of complement on the attachment of virulent, motile $\mathrm{T}$. pallidum (Tp) to human mononuclear leucocytes

\begin{tabular}{lll}
\hline & $\begin{array}{l}\% \text { oftached } \\
T p^{*}\end{array}$ & $\begin{array}{l}\text { \% cells with } \\
\text { attached Tp }\end{array}$ \\
Complement only & 98 & \\
& $(96-100)$ & 42 \\
$20 \%$ heat-inactivated normal serum & & $(37-47)$ \\
Human with complement & 87 & 38 \\
Rabbit with complement & $(72-98)$ & $(26-46)$ \\
20\% fresh normal serum & 94 & 38 \\
Human & $(79-100)$ & $(25-56)$ \\
Rabbit & 97 & 42 \\
& $(96-100)$ & $(36-52)$ \\
\hline
\end{tabular}

Values represent the mean and range of five experiments

*Percentage of the total number of treponemes remaining on the glass coverslip after incubation, washing and fixation adhering to leucocyte cell surfaces

When heated, non-motile treponemes were incubated with phagocytes only $14 \%$ of treponemes appeared to be attached to cells (Table 3). Normal human or rabbit serum and complement did not increase the frequency of attachment. The frequency of attachment was less than $6 \%$ when incubation was performed on a mechanical shaking device to compensate for absence of motility in the heated treponeme. The small percentage of heated, nonmotile treponemes which appeared to be attached to cells in fixed preparations may not actually be adherent to the cell surface as no attachment was observed during incubations with unfixed preparations. In wet, unfixed preparations ingestion of heated, non-motile treponemes was not observed.

$\dagger t$ test with 24 degrees of freedom where $t=1 \cdot 3620$
Table 3 Attachment of heated, non-motile T. pallidum $(T p)$ to human mononuclear leucocytes with or without normal serum and complement

\begin{tabular}{lll}
\hline & $\begin{array}{l}\% \text { attached } \\
T p^{*}\end{array}$ & $\begin{array}{l}\% \text { cells with } \\
\text { attached } T p\end{array}$ \\
\hline No serum or complement & 14 & 7 \\
$20 \%$ heat-inactivated normal serum & $(12-16)$ & $(4-9)$ \\
Human with complement & 8 & \\
Rabbit with complement & $(6-11)$ & $(3-5)$ \\
& 5 & 2 \\
& $(4-7)$ & $(2-3)$ \\
\hline
\end{tabular}

Values represent the mean and range of three experiments

*Percentage of the total number of treponemes remaining on the glass coverslip after incubation, washing and fixation adhering to leucocyte cell surfaces

To show that treponeme suspensions from rabbit testes did not inhibit phagocytosis suspensions other than polystyrene latex were added to the incubation mixtures. Thus, heat-killed staphylococci, viable Toxoplasma gondii, and zymosan were all ingested by phagocytes whereas $T$. pullidum remained attached to the cell suiface.

Ingested $T$. pallidum were not seen in any of the preparations. However, since intracellular treponemes may not be readily identifiable by phasecontrast microscopy, electron microscopy was performed on preparations in which $100 \%$ of the phagocytes showed attached treponemes in the presence of $20 \%$ heat-inactivated normal human serum and guinea-pig complement. For this it was necessary to use treponeme concentrations of $2 \times 10^{8}$ per $\mathrm{ml}$. No intracellular treponemes were observed in such preparations.

\section{Discussion}

Studies of the immunobiology of $T$. pallidum have been hindered by the inability to cultivate the virulent treponeme in vitro, by damage to the organism by extraction procedures, and by the effect of substrates such as extraction medium ingredients and rabbit testicular debris on in-vitro preparations. Techniques established in this laboratory have been used in an effort to preserve the fragile surface constituents of the treponeme and the in-vitro function of mononuclear phagocytes. The organism was extracted rapidly from rabbit testicular slices and subjected to a short centrifugation only to avoid trauma before use in phagocyte preparations. Thus treponemes were incubated with phagocytes only 30 minutes after slicing the rabbit syphilitic testes in contrast to the more lengthy anaerobic TPI test extraction technique. The extraction medium, RPMI-1640, which is a tissue culture medium without antibiotics or 
reducing agents, sustained aerobic treponemal motility for at least three hours and was employed routinely for in-vitro macrophage cultivation in preference to the TPI test medium. The system is simple, reproducible, and convenient. Only a few treponemes in the suspension remained on the monolayer after they had been incubated, washed, and fixed, probably because of their motility and small mass. Recently techniques have been developed in this laboratory in which T. pallidum is centrifuged directly on to cell monolayers (unpublished data).

Previous investigators have shown that virulent $T$. pallidum may adhere to a variety of surfaces including normal human erythrocytes and eukaryotic cells in tissue culture (Nelson, 1953; Fitzgerald et al., 1975). By contrast, heated, non-motile treponemes and avirulent, cultivatable treponemes (Treponema denticola and Treponema phagedenis biotype Reiter) do not adhere to cultured rabbit testicular cells in tissue culture (Fitzgerald et al., 1976).

We have demonstrated that $T$. pallidum also adheres to the surface of human mononuclear phagocytes as well as those of the rabbit and mouse. Attachment is not complement-mediated as described for other particles requiring specific receptor sites (Mantovani et al., 1972). Attachment is also not due to 'immune adherence', as described by Nelson, since the treponeme extracted by TPI test methods does not require complement or syphilitic serum for adherence to cell surfaces (Nelson, 1953). Heated, non-motile treponemes do not attach to human mononuclear phagocytes. Preliminary studies in our laboratory indicate that non-pathogenic treponemes ( $T$. phagedenis biotype Reiter and $T$. refringens) also do not attach to mononuclear phagocytes in vitro. These findings suggest that specific surface constituents on virulent, motile treponemes may be important in the attachment process but this adherence is non-specific since these organisms may also attach to a variety of substrates, including normal human erythrocytes and eukaryotic cells in tissue culture (Nelson, 1953; Fitzgerald et al., 1975).

As shown in these studies, attachment is polar with the terminal portion only of the treponeme adhering to the cell surface. Morphological studies have shown that the terminal portions of treponemes differ from the rest of the body (Hovind-Hougen, 1976). Electron microscopy with negative staining has shown that the terminal portions of treponemes have three zones of varying density, whereas the remainder of the organism is relatively homogeneous. Their shape may be species-specific. Thus avirulent treponemes cultivated in broth have tapered or blunt ends whereas pathogenic treponemes have pointed ends. The relationship between these morphological differences and attachment awaits further study.

Attachment of virulent, motile treponemes to phagocytic cells without subsequent ingestion suggests that virulent $T$. pallidum may have antiphagocytic surface factors. These observations are consistent with previous electron microscopical examinations of human syphilitic chancres in which treponemes were mainly extracellular, although a few intracellular treponemes were seen mainly in non-phagocytic cells (Azar et al., 1970; Sykes et al., 1974). These studies, however, described fixed specimens in which the motility and viability of intracellular or extracellular organisms could not be assessed. Thus, the few intracellular treponemes identified in these reports may not have been fully intact at the time of their ingestion. Since treponeme viability cannot be quantitated by in-vitro cultivation at the present time, it is important that studies of treponeme-phagocyte interaction include unfixed preparations to differentiate motile from nonmotile organisms.

The initial interaction of $T$. pallidum with human mononuclear phagocytes in vitro demonstrates that virulent, motile treponemes attach to the surface membrane but are not ingested by these cells. Studies are now in progress to examine subsequent interactions of these organisms with phagocytic leucocytes.

This investigation was supported by Training Grant No. AI 00465 and Research Grant No. AI 12932 from the National Institutes of Health.

We thank Ms Patricia DeNunzio for her technical assistance and Dr Thomas C. Jones, for his advice and assistance in electron microscopy.

The authors are indebted to Dr Paul H. Hardy, Jr. of the Johns Hopkins Medical Institutions for his advice and co-operation in the cultivation and study of virulent Treponema pallidum.

\section{References}

Azar, H. A., Pham, T. D., and Kurban, A. K. (1970). An electron microscopic study of a syphilitic chancre. Archives of Pathologv, 90, 143-150.

Fitzgerald, T. J., Miller, J. N., and Sykes, J. A. (1975). Treponema pallidum (Nichols strain) in tissue cultures: cellular attachment, entry and survival. Infection and Immunity, 11, 1133-1140.

Fitzgerald, T. J., Miller, J. N., Sykes, J. A., and Johnson, R. C. (1976). Tissue culture and Treponema pallidum. In Biology of Parasitic Spirochetes, p. 57. Edited by R. C. Johnson. Academic Press: New York.

Gordon, S., Todd, J., and Cohn, Z. A. (1974). In vitro synthesis and secretion of lysozyme by mononuclear phagocytes. Journal of Experimental Medicine, 139, 1228-1248.

Griffin, F. M., Jr, and Silverstein, S. C. (1974). Segmental response of the macrophage plasma membrane to a phagocytic stimulus. Journal of Experimental Medicine, 139, 323-336. 
Hederstedt, B. (1961). A comparative study of immobilizing and hemolytic complement activity. Acta pathologica et microbiologica Scandinavica, 53, 180-190.

Hovind-Hougen, K. (1976). Treponema and Borrelia morphology. In Biology of Parasitic Spirochetes, p. 7. Edited by R. C. Johnson. Academic Press: New York.

Magnuson, J. J., Eagle, H., and Fleischman, R. (1948). Minimal infectious inoculum of Spirochaeta pallida (Nichols strain) and consideration of its rate of multiplication in vivo. American Journal of Syphilis, Gonorrhea, and Venereal Diseases, 32, 1-18.

Mantovani, B., Rabinovitch, M., and Nussenzweig, V. (1972). Phagocytosis of immune complexes by macrophages. Journal of Experimental Medicine, 135, 780-792.

Metzger, M., Hardy, P. H., Jr, and Nell, E. E. (1961). Influence of lysozyme upon the treponeme immobilization reaction. American Journal of Hygiene, 73, 236-244.
Musher, D. M., Izzat, N. N., Min, K. W., and Gyorkey, F. (1972). In vitro phagocytosis of avirulent $T$. pallidum by rabbit macrophages. Acta dermato-venereologica, 52, 349-352.

Nelson, R. A., Jr (1953). The immune-adherence phenomenon. Science, 118, 733-737.

Nelson, R. A., Jr, and Diesendruck, J. A. (1951). Studies on treponemal immobilizing antibodies in svphilis. Journal of Immunology, 66, 667-685.

Robbins, S. L. (1967). Patho!ogy, third edition, p. 302. Saunders: Philadelphia.

Sykes, J. A., Miller, J. N., and Kalan, A. J. (1974). Treponema pallidum within cells of a primary chancre from a human female. British Journal of Venereal Diseases, 50, 40-44 